\title{
Fragmentation of the Fe/male Characters in Final Flight from Sanaa: A Corpus-based Feminist Stylistic Analysis
}

Ohood Ali Mohammed Saif Al-Nakeeb*

Department of Linguistics, University of Kerala, TC: 14/1170(1), St. George Lane, Kumarapuram, Trivandrum, Kerala, India

Corresponding Author: Ohood Ali Mohammed Saif Al-Nakeeb, E-mail: just_meee23@yahoo.com

\section{ARTICLE INFO}

Article history

Received: December 24, 2017

Accepted: February 04, 2018

Published: May 01, 2018

Volume: 7 Issue: 3

Advance access: March 2018

Conflicts of interest: None

Funding: None

\begin{abstract}
This paper examines the fragmentation of the fe/male characters in a one-novel corpus (henceforth, FFFS Corpus). The text is Final Flight From Sanaa, a Yemeni novel written by Qais Ghanem and published in 2011. The paper unfolds how the fe/male characters are introduced and talked about as anatomical parts in order to describe differences or similarities in gender representation, and to explore power relations and cultural differences between the eastern and western men and women. The analysis is done qualitatively using the feminist stylistic approach set out in Mills (1995) and quantitatively with the help of the corpus linguistic tool Wmatrix. Results have demonstrated that although the female and male bodies are almost equally fragmented, they are depicted differently. For example, female characters are introduced in terms of their physical attractiveness and sexuality while their male counterparts are focalized via their colors, physical deficiencies, skills, personality traits and the level of power they possess (whether physical or social).
\end{abstract}

Key words: Fragmentation, Feminist Stylistics, Corpus-based Analysis, Wmatrix

\section{INTRODUCTION}

This paper exploits the technique of fragmentation in the analysis of the bodies of the female and male characters in prose fiction. The word fragmentation is a definition by itself. It simply means breaking a whole thing into fragments, thus a contrast to the term wholeness. The term is used in so many areas of study such as biology, literature, pornography, film criticism, arts, etc. However, feminists mainly exploit it in accordance with the female body in the analysis of images, statues, sculptures, movie scenes etc. It can be used either to represent women negatively or positively. Kappeler (1986) concerns the word and the image representation of women in pornographic literature and visual arts and argues that women in pornography are being deprived from their subjective being and reduced into objects. Such a negative perspective is challenged in Guldin (2002) who argues that fragmentation does not cause unity loss, rather accentuates the individuals' characters and the importance of each of their organs "in which specific aspects of culture are imagined to reside" (pp. 224-8). There are postcolonial studies that have shown the positive aspects of being fragmented in literature (as Katrak, 2006; Green, 2016; Morguson, 2012). Morguson, for example, argues that fragmentation of the female characters fiction indeed serves their empowerment, their understanding of their wholeness and their survival as individuals.

In linguistics, and particularly in the feminist stylistic perspective, Mills (1995) concerns the construction (negative, positive or neutral) of both the female and male bodies. Mills defines fragmentation as "the process whereby characters in texts are described in terms of their body-parts instead of as people" (p. 207). That is, a character's body is fragmented when its anatomical parts such as face, eyes, nose, limbs, etc. are talked about in details and when these are associated or compared to objects or nonhuman entites (a process also known as objectification). Fragmenting characters' bodies in texts and evaluating or nonevaluating them conveys ideological messages and positive or negative attitudes and investigating this technique can reveal a number of things about these ideologies and attitudes. Furthermore, stylisticians as Jeffries (2007) and Mills (1995) whose general interest is to find out how language is exploited to convey attitudes towards people, characters, situations, ideologies, etc. consider the linguistic construction as a gate to understand the cultural and social portrayals of the female (body) in texts.

The concern with the cultural, social and political construction of the 'body' in the feminist theory is evident in the discussions of distinctions between sex and gender. In her book Bodies that Matter: On the Discursive Limits of "Sex", Judith Butler (1993), on which Mills' approach (1995) is informed, questions the materiality of 'body'. She argues that "for surely bodies live and die; eat and sleep; feel pain, pleasure; endure illness and violence; and these 'facts,' one might skeptically proclaim, cannot be dismissed as mere construction". These are "primary and irrefutable experiences", however, "bodies only 
appear, only endure, only live within the productive constraints of certain highly gendered regulatory schemas" (p. xi). That is, sex and its materiality 'body' are formed via the workings of power relations. Butler (1990) has already tackled the distinction of sex vs. gender in her book Gender Trouble: Feminism and the Subversion of Identity and has contested the common view that sex is the biological difference while gender is the cultural difference between males and females. Instead, Butler proposes that both sex and gender are socially and culturally constructed and "perhaps it [sex] was always already gender, with the consequence that the distinction between sex and gender turns out to be no distinction at all" (p. 6-7). Butler (1993) argues that "gender is the repeated stylization of the body, a set of repeated acts within a highly rigid regulatory frame that congeal over time to produce the appearance of substance, of a natural sort of being" (p. 33). Butler (2015) also argues that "we are assigned gender" and "gender assignment is the first act of gender construction". Butler (1993) defines sex as "an ideal construct which is forcibly materialized through time. It is not a simple fact or static condition of a body, but a process whereby regulatory norms materialize 'sex' and achieve this materialization through a forcible reiteration of those norms" (pp. 1-2). Therefore, she lays the argument that social and cultural construction is applicable to the sex, the gender and the body which are bound by power relations.

Scrutinizing the construction of the characters' bodies in this paper is significant in two senses; cultural and methodological. The first is that it will contribute to the less-researched area of feminist criticism of the Yemeni literature, hopefully allowing for an understanding of the cultural representation of gender in Anglo-Yemeni literature. Second, with the presumption that cultural differences can be investigated using corpora, this paper presents a new methodology that is the integration of the qualitative approach of fragmentation set out in Mills (1995) with the quantitative method of analysis realized in the corpus linguistic web tool Wmatrix. Accounting for cultural differences using corpora has been discussed by Leech \& Fallon (1992) who argue that it is difficult to believe that there is an objective method for studying the numerous social, institutional, linguistic, and other factors which distinguish one culture from another" (p. 31). However, they attempt to distinguish British and American cultures via keyword analysis of two corpora Brown and LOB.

\section{Research questions}

The principal aim of this paper is the investigation of the textual representation of the fe/male bodies of the characters in FFFS Corpus. In order to achieve this aim, answers to the following questions are attempted.

1. How are the fe/male characters and their bodies introduced and described in the corpus?

2. How are power relations between female and male characters, and between characters who are assigned the same gender, constructed via lexical and syntactic structures and what are their implications?

3. How are the characters' anatomical parts exploited to represent the Arabic (Yemeni) culture in comparison to the western one?

\section{THEORETICAL FRAMEWORK}

\section{Feminist Stylistics}

As the title of the approach suggests, it is an integration of feminism and stylistics. The feminist part of the approach "aims to draw attention to and change the way the gender is represented", and its stylistic aspect concerns the description of sexism in texts and the analysis of "the way that point of view, agency, metaphor, or transitivity are unexpectedly closely related to matters of gender". Drawing techniques from literary as well as linguistic backgrounds, feminist stylistics equips readers (including analysts) with "a vocabulary to describe what is going on in texts and what is going on in the readers themselves when they read" (Mills, 1995, pp. 1-2). Thus, this process creates an awareness of "the way that language choices may serve the interests of some people to the detriment of others".

There are a number of reasons concerning the selection of feminist stylistics over other feminist models provided in literature. First, feminist stylistics differs from mainstream critical discourse approaches in the sense that it does not "marginalize the importance of specifically gendered identities and the social inequalities which these contribute" (Walsh, 2001, p. 27). Second, unlike other feminist approaches focusing on women representation, feminist stylistics concerns the representation of gender in general. It concerns "how women and men are constructed at a representational and at an actual level" (Mills, 1995, p. 3). Third, Mills' model is indeed an account of how gender is represented with an aim for a change at the linguistic as well as the social level. Fourth, feminist stylistics is not only text oriented but also invites contextual elements of texts and "the polyvalence of language items themselves" (Mills, 1995, p. 197) while interpreting the relation between language and ideology in texts. Fifth, different levels of language are considered in the approach.

Indeed, Mills' feminist stylistic analysis of language choices is done on three levels; words, phrases/sentences and discourse. Analysis at the level of words include, for example, looking at the sexist use of the generic pronoun 'he', generic nouns such as 'mankind', the generic use of 'man' as a prefix or suffix, gender specific naming, derogatory terms, endearments and diminutives, euphemistic terms and taboos, lexical gaps, etc. At the level of phrases and sentences, the concern is with the sexist use of phrases, metaphors, jokes, and so on.

Besides analyzing individual words, phrases and sentences, feminist stylistics is concerned with analysis at the level of discourse, where consideration is given to the ways in which characters are constructed in texts, that is to how they are described and how they describe themselves. Moreover, discoursal analysis concerns the roles assigned to fe/male characters and the fragmentation of their body parts. Other concerns of discourse analysis in this approach include point of view and focalization, and larger discursive framework of analysis realised in schemata. Representing women as having problems and in need of advice, and the 'before and after' structure are another two common discursive frame- 
works. These frameworks might be gendered and taken as common sense knowledge. Thus, "it is only by describing these seemingly common sense structures that we will begin to expose their constructed nature and at the same time their perniciousness" (Mills, 1995, p. 187). The discursive framework selected for investigation in this paper is fragmentation. Fragmentation, argues Mills (1995), has two important effects. The first is to represent the character's body as depersonalized, objectified, and reduced to its parts and the second is to unfold the focalizer of the female body which is in this sense commonly done by the male gaze.

\section{Previous Studies}

Viewing the female body via its anatomical parts and in comparison to objects has been the concern of feminist critics. This section will shed a critical light on a number of studies falling in the area of feminist literary criticism and feminist stylistics. Studies within feminist literary criticism include Innes-Parker (1995), June (2010) and Brown (2012). Innes-Parker (1995) does a literary feminist criticism of the thirteenth century western religious texts written for women known as anchoresses and finds that the anchoress body, in these texts, is fragmented and reconstructed via the use of erotic and fertile metaphors and imagery "combined with images of motherhood and fertility in order to present the anchoress's union with Christ as both a sensual union with her divine lover and reenactment of the Incarnation" (pp. 51-2). The anchoresses' body, furthermore, "is fragmented, both literally, in the suffering which described using images of illness or wounding, and metaphorically, as her tendency to sin is discussed in terms of the individual senses and the body parts associated with each (ear, eye, mouth, hand, etc.)" (p. 35). Her body is fragmented via images of nest, fig tree, etc. and is reconstructed as "the sealed chamber that encloses and protects the pure heart as the anchoress prepares to receive Christ"; as "the vessel that bears Christ in erotic union and communion"; as "the bower in which she dallies with Christ"; "the womb which encloses and nurtures him"; garden, arbor, inn, etc. (p. 52).

June (2010: 2) approaches fragmentation of the female body from a literary postmodernist perspective. Her data is based on the postmodernist multiethnic American women's novels of the mid 1970s through the 1990s. Her study concerns exploring "how fragmentation has defined women's position in the United States, and how recent, multiethnic American women authors have embraced a disjointed, postmodern writing style both to reflect and to resist their historical state of fragmentation". She focuses on the two graphic symbols the wound and scar and how they work textually in fiction to manifest versified forms of oppression. These, she argues, carry female characters towards the journey of collective discovery of the female community. June finds that the authors of these novels use fragmentary style of writing in order to resist and subvert different forms of oppression including patriarchy, racism, and heteronormativity.

Like June (2010), Brown (2012: 4) takes into account a literary feminist perspective while analyzing eight novels.
However, she extends the analysis of texts to include visual arts such as photos, collage, video, objects, etc. as represented in the works of contemporary, postmodern visual artists. She looks at works belonging to a time span from the 1975 to 2010 investigating how the diversity of the novelists and artists belonging to this period "negotiate shifting definitions of U.S. citizenship through their intensely performative texts", and "particularly how writers and visual artists talk to each other and back to society through their respective aesthetic forms" (p. 7). She argues that "each of their novels or artworks (...) rely on various dimensions of the black aesthetic to represent and meditate on the black body. That which defined what an American citizen most emphatically was not, the black body, and certainly the black female body" (4).

Among the feminist stylistic studies are Jeffries (2007) and Montoro (2012). Jeffries (2007) provides a critical discourse approach for the textual construction of the female body. Jeffries qualitatively investigates a large body of data (86 texts) derived from women's magazines; mainly slimming, pregnancy and plastic surgery magazines (published in February 2000). The analytical tools employed in analysis are basically Hallidayan in nature, specifically concern the textual ideational features realized in the following functions; naming, describing, equating, contrasting, enumerating, assuming, implying creating time and space, presenting processes and states, and presenting opinions. The major finding of the study is "what magazines published for the mass market are presenting to us and our daughters is an ideology of the body which emphasizes the stable, youthful and clean (unleaky) body over the real lived experience of women" (p. 194).

Montoro (2012) does a corpus stylistic analysis of the genre Chick Lit which she also terms Cappuccino Fiction (fiction written by women, about women and for women) attempting to examine the stylistic and the linguistic features "that embody and project the narrative, sociological and feminist issues, among others, that jointly typify this genre" (p. 1). She employs a number of methodologies in analysis and with regard to the corpus stylistic part of the study, Montoro compiles a corpus running into 650,000 words of six novels. She approaches the corpus using Wmatrix. Montoro looks at almost all semantic domains including B (the body and the individual). She concludes that the novels she has investigated "pay less attention to anatomical matters than the texts in the reference corpus", and that "the body issue and over-obsessive preoccupation with appearance so often described by scholars do not seem to manifest linguistically, as references to anatomy are under-used with regard to other fictional genres" (pp. 95-7).

What sets the feminist analysis provided in this paper is its concern with both female and male bodies. Indeed, it demonstrates the differences and similarities in political and cultural construction between characters of the same sex/ gender, that is between male characters and female characters categorized either as western or eastern on one hand and between characters of different gender, that is between female and male characters, on the other. 


\section{METHODOLOGY}

\section{Data}

Final Flight from Sana'a, published in 2011, is the first novel by Qais Ghanem, a retired clinical professor of medicine in Canada who has also written Two Boys from Aden College (2012) and Forbidden Love in the Land of Sheba (2014). The novel is about Tariq, a Yemeni doctor living in Canada, and his journey of return to Yemen. He is a divorced man whose wife abandons him for another man. His relationship with his barfriend Colin, a lawyer, leads to a business trip to Yemen in order to introduce medical machines to the country. In Yemen, he gets involved with the rape case of Muna, the daughter of an old friend (Farook), and eventually he is arrested by high officials and is sent to prison. Gita, a western married woman who had had an affair with Tariq, travels to Yemen to rescue him. She succeeds and they both leave Yemen. In the airport, and on his way back to Ottawa, Tariq falls down and loses consciousness, thus marking the end of the novel.

The novel, after taking the consent of the author, was made into a corpus entitled FFFS. It was manually processed and edited by deleting the front cover, the preface, headings and the author's biography. The remaining text is the bulk of the novel running into 59,906 words. It was, then, electronically stored as a txt file and uploaded to the web software tool Wmatrix. The corpus is small in nature which gives more space for the analyst to investigate every related concordance with an aim to formulate a detailed analysis of the linguistic choices associated with each character and culture.

\section{Analytical Tool}

Wmatrix is a web tool that is developed by Rayson (2009) at Lancaster University and based on USAS corpus annotation system. Unlike other corpus web tools and softwares, Wmatrix mixes POS tagging and semantic field annotation and moves from keyword analysis to analysis of key semantic domains, thus extending keywords procedure to identifying key grammatical categories and key concepts. The semantic tagset used in this system includes 21 major discourse fields, namely A general and abstract terms; $\mathrm{B}$ the body and the individual; $\mathrm{C}$ arts and crafts; $\mathrm{E}$ emotion; $\mathrm{F}$ food and farming; $\mathrm{G}$ government and public; $\mathrm{H}$ architecture, housing and the home; I money and commerce in industry; K entertainment, sports and games; L life and living things; $\mathrm{M}$ movement, location, travel and transport; $\mathrm{N}$ numbers and measurement; $\mathrm{O}$ substances, materials, objects and equipment; P education; Q language and communication; S social actions, states and processes; T time; W world and environment; X psychological actions, states and processes; Y science and technology; and $\mathrm{Z}$ names and grammar. The main focus of this paper is the investigation of the major semantic domain $B$, more specifically the sub domain B1 (the body and the individual).

\section{Procedure}

The first stage is annotating the text selected for analysis; that is, uploading it to the web and processing it via semantic tagging. The second stage in the analysis is identifying all characters in the novel (names, sex, origin); qualitatively via close reading and quantitatively using the major semantic domain $\mathrm{Z}$ (names and grammar) in Wmatrix (Rayson, 2009). The third stage is, using Wmatrix, identifying words related to the human body under the sub category B1 and excluding irrelevant words such as those that are related to objects, food (e.g. legs of a table) or grammatical functions (e.g. back up). This stage and also the following stages involve manually counting the occurrences. The fourth stage is classifying those anatomical parts on the basis of the sex of the characters, then classifying them in categories on the basis of their shared topoi. Classification of the B1 list into categories goes hand in hand with the objectives of the study. The final stage is interpreting the grammatical and discoursal associations of the listed words with other words in context, that is in KWIC concordances, and how these contribute to constructing gender depictions, power relations and cultural differences. Grammatical associations include choices that concern doers of actions, that is whether they are in control of their bodies and act accordingly or they are acted upon by others. The study of discoursal associations involves analyzing focalization and discourse prosody (negative or positive) which is realized in evaluative expressions spread along the corpus.

\section{RESULTS AND DISCUSSION}

\section{Characters}

Identifying characters names under the semantic sub category Z1 demonstrates 91 types with a total frequency of $366(0.65 \%)$. The list, however, does not show all names of characters such as the different spellings of Tariq. This list shows only 'Tariq Hakim' as the main character, though 'Tariq' appears 372 times (as shown in word frequency list). Magda, Gita and other eastern names are not shown here as well due an eastern oriented way of spelling names which are only recognizable under the semantic category Z99. Overall, there are 20 male characters including Tariq, Colin, Boris, Farook, Taha, Abu-bakr, Taher, Abdulateef (Minister of National Secuirty), Ali Ahmed, Brian, Erik, Omar, Abdulla Ali, Ahmad Murad, Fares, Gordon, Federico, Abdulwahab Murad, Mustapha Akbari, Yehia Yamani. Other anonymous characters include the porters, airport officers, porters, kidnapers, etc. On the other hand, there are only 9 female characters, namely Gita, Muna, Magda, Samantha, Lubna, Susan, Brenda, Mrs Williams. Gharam. Other anonymous characters include female patients, a lady in a restaurant, etc. The frequency of occurrence of the male characters is 820 in comparison with female characters whose names only occur 208 times. This is not an implication that this unequal distribution of characters is significant to the representation of sexes because at times the representation of one female character can outweigh the representation of ten or more male characters and vice versa. Rather, this unequal distribution of characters can be significant and may add to the overall arguments stated in the analysis below. 


\section{Fragmentation of Body Parts}

In Wmatrix, the sub category B1 features all the words related to the body, including anatomical parts (e.g. head, leg, etc.) and body needs and actions (e.g. peeing, sleep, awake, etc.). The number of words that are listed in this semtag is 697 in the whole corpus, of which 380 are associated with the male body while 209 are employed in reference to the female body and 10 instances where both female and male characters appear collectively. The rest concordances, 98 in number, are excluded from analysis because they are either referents to objects and food or they have grammatical functions, etc.

Classification of the selected concordances for interpretation is done to show their semantic functioning in the corpus. Some are employed in concordances where characters are introduced, where power relations can be demonstrated, where love scenes are described and cultural differences are constructed. The following Figure 1 shows classification of words in $\mathrm{B} 1$ on the basis of their semantic functioning and their roles in representing characters and cultures.

\section{Introducing characters}

The female body. The female characters in this corpus are introduced in terms of their appearances, sexual attractiveness and sexual availability. There are 37 concordances in which female characters are introduced in the course of actions in the whole novel. These concern the focalization of the western and westernized characters on one hand and eastern (Yemeni and Libyan) female characters on the other. Samantha, the first female western character to be introduced in the novel, is focalized from a male perspective. She is evaluated as sexually attractive via the linguistic idiomatic expression 'she had turned a few heads', and via the evaluative adjective 'gentle' in 'the gentle tremor of her breasts'.

The westernized Magda, one of the major female characters, is also focalized from a male gaze and introduced as 'distinctly Middle Eastern, with black wavy hair...dark eyes... and light, olive-brown skin and heavy lipstick...quite pretty', having 'a lovely face' and elsewhere in the context 'gorgeous'. She also introduces her age to Tariq as 'past menopause' which is a reference to her femaleness and talks

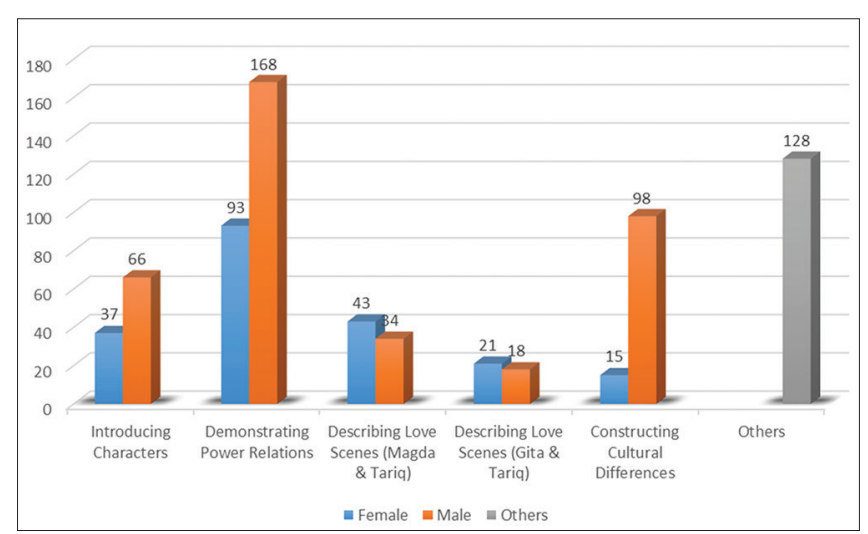

Figure 1. Fragmentation of $\mathrm{Fe} /$ male Body Parts and their Functionings about her mum saying 'my mother, with nearly blond hair, very fair skin and green eyes' where the focus is on her body not on motherhood features.

Moreover, Gita, the western female character, is presented as a stereotype, i.e. the kind of woman who has 'a round pleasant face, blond hair, blue eyes' and wearing 'heavy lipstick on full lips'. Her beauty is referred to more than once, first when she meets Tariq, second when she goes to Yemen and meets the driver who 'was stuck by her fine blond hair', third when the driver introduces her to the solider 'look at her blond hair'. Even when Tariq dreams about her when he is in prison, she is described as 'stunningly beautiful and suntanned'. She is also focalized as a tender woman whose 'tears' are 'welling in her eyes' when she waves goodbye to Tariq.

Elsewhere in the corpus, Lubna, the westernized character is also introduced in relation to her tenderness as when she blushes when her boyfriend touches 'her hand' and who plants a long kiss on Tariq's cheek considering him as her father. Typically, she had also been presented as a 'young pretty olive-skinned woman of between twenty and twenty-five', thus foregrounding three common characteristics of a desirable woman namely youth, beauty and tenderness.

On the other hand, beauty and tenderness do not feature the Libyan character Gharam, Taher's wife, who is critically introduced to the readers via her dress code. She appears "wearing black hijab completely enveloping her head and body except for most of her face' as an indication of the gazer's concern with her dress code not with her having a (non) attractive appearance. There are no evaluative adjectives or adverbs in the concordance. She is not considered attractive nor ugly. She is simply referred to in terms of her religious affiliation, as a Muslim.

The male focalizer carries the same attitude when introducing the three Yemeni women in the hospital. He is confused to see women 'without the niqab' walking in Yemen; 'Tariq witnessed pandemonium when three women in their hijab, but without the niqab entered the hall'. Furthermore, when a female Yemeni woman is seen in a restaurant she is introduced as wearing 'full black hijab, including the niqab, covering her entire face except for the two rectangular holes for her eyes'. The male focalizer is surprised to see this woman eat and drink while still wearing the 'niqab' (repeated 4 times), 'the woman had to lift the niqab off the lower part of her face giving the spoon just enough room to find her mouth and would then let go of the niqab. Amazingly, her niqab remained clean and dry... the woman was lifting her niqab in order to sip from her cup'. Overlooking the word 'niqab' in this concordance denotes the critical stance of the focalizer towards the Yemeni women's dress code.

The male body. Like the female characters, physical fragmentation of the male body is noticeable in the novel. However, the depiction of their fragmented anatomical entities carries a different meaning. Male characters are not sexually attractive, tender or beautiful. Rather, they are depicted via their origin and color, their outfit, personality traits and physical deficiencies.

The three characters that are positively represented are Tariq, Federico and Colin. The protagonist Tariq is the 
most talked about male character in the novel. His name is mentioned 404 times followed by Colin (87 times). Tariq is, first, introduced via his color. He's 'brown-skinned' and later, referred to as 'brown man' in 'their eyes met and the brown man said'. It signifies his difference, his identity. One thing to note here is that Tariq is not identified as a 'Yemeni', rather he is of a 'Yemeni origin'. It is emphasized linguistically through the association of the verb 'born' with him in many concordances. This could be related to the author himself who does not identify himself as a Yemeni either, rather as 'was born in the British Colony of Aden, later, part of Yemen'.

Second, Tariq is described as 'gray-haired, slightly built man' who is 'about five feet eight inches tall'. As seen here there is no reference to the size of his eyes or lips. What is focalized here is the color of his hair, the size of the overall body and height. Tariq, along with other Yemeni male characters, is focalized via his height. However, he is positively depicted as 'five-feet eight inches tall' which is a detailed description of his height, while other characters are portrayed as bluntly 'short'. The only other characters described as 'tall' are his rivals; the men who kidnap him and Gordon. The latter is the man whom Tariq's wife left him for. He is described as 'Gordon was tall and good looking, but quite average otherwise, no wit, little humor, always looking for sympathy, and quite talkative for a man, mostly about himself'.

Third, there is a detailed description of the color and material of Tariq's clothes as in 'dressed in dark gray pants, a plain beige shirt with a brown and gold tie, and a light gray tweed jacket, with dark gray leather elbow patches'. However, there is no detailed description of his body parts. Fourth, there is a reference to Tariq's age and attractiveness i.e. 'he estimated his age to be 65 . He looked Caucasian; not handsome by any stretch of the imagination but with a halo of respectability around him'. Thus, his attractiveness is not the product of his anatomical parts or overall beauty, rather it is attributed to his social rank. In another context, Tariq's potentiality is evident as he is able to use a map to walk to the hotel in a newly visited city. He is also portrayed as decisive and trustworthy.

Colin, Tariq's Canadian friend, is, moreover, introduced via his color and origin; 'after all, he was the native regular white Canadian, born in the city only one mile away from the pub'. Furthermore, Federico is the first male character to be introduced in the novel. He is described as having the physical ability to 'waive his arms about' while talking and 'gesticulating' while also holding 'the beer mugs in his hands'.

On the other hand, the other male characters are introduced negatively such as Boris, Taher and the Yemeni male characters. These, along with the rest of Yemeni characters, are introduced negatively as physically deficient, even if they have social power. Boris is introduced as a 'big man with large protuberant belly' and has 'a ruddy complexion' and 'large and thickened red nose'. He has a 'rhinophyma', a medical problem which causes a short sleep, followed by a snort, while conversing with others. The narrator describes him as a 'big fat middle-aged male with sleep apnea', thus foregrounding his deficiency.
Another male character who is negatively focalized is the Libyan Taher who is focalized as 'a short fat man with a big belly', 'a double chin', 'prominent eyes', 'and a goatee'. The Yemeni male characters are portrayed via their dress code, color, ugliness, physical deficiencies. They are also depicted as corrupted men in power. Although the Yemeni Sheikh is introduced as 'a distinguished-looking man, in his sixties, and wearing traditional Yemeni clothing: a turban, the obligatory dagger', having 'a thick but well-groomed beard that was died brick red with henna', 'a very important and very witty man' and 'very friendly and welcoming', the context in which he is introduced indicates a sarcastic outlook of the greeting custom in Yemen (more will be mentioned in the analysis of culture).

Characters that are introduced in terms of their physical power, color and origin are the soldiers, officers, porters and bodyguards. These are equally described as 'tall', 'big' and 'muscular', having 'huge hands' and are 'fully armed'. They are 'smelly' and 'sweaty' and do not belong to Yemen. For example, the men who kidnap Tariq are 'tall, black, and muscular and very sweaty, they have curly hair' and 'their size and physique'. Such characteristics are not of Yemenis. Furthermore, the officer who rapes Muna is 'surprisingly big and muscular for a Yemeni with a goatee' and 'a beard'. The evaluative adverb 'surprisingly' in this sentence lends support to the previous argument.

\section{Demonstrating levels of physical and social power}

The female body. Two levels of power distribution are identified in the concordances (93) related to the female characters, i.e. social power and (physical and social) weakness. The two extremes are representations of the two characters: Tariq's female western patient (anonymous) and Muna (the Yemeni female character who is suffering from convulsions due to a rape). The former is represented as socially empowered while the latter is physically and socially submissive.

Concordances in which the western female patient is talked about are 15 in number. Thirteen of these are predetermined by the definite article 'the' either directly as in 'the breast', premodified by evaluative adjective phrases as in 'the painful muscle', or described via adjectives as 'numb' in 'it [muscle] was cold and numb'. The other two body parts 'breasts' are respectively premodified by the possessive adjective 'her' in 'he had exposed her breasts unnecessarily' and the definite nominal phrase 'the woman's' in 'I still cannot understand why you had to expose the woman's breast in order to spray it'.

The definite article 'the' in the 13 examples mainly precedes technical terms and is deployed to distance both characters (the patient and Tariq). The patient is already distanced when her name is not revealed in the novel and when her body is separated from her total being when its parts are associated with 'the'. This, thus, results in the representation of the medical problem rather than of the female body and reinforces Tariq's position as a doctor, who has no intention in exploiting her sexually. What is notable, though, in the two fragments where possessive 'her' is used, is an emphasis of disapproval of both the woman and the inspector, of the 
medical procedure Tariq has chosen to perform on her. This is evident in the evaluative adverb 'unnecessarily', and the inspector's statement 'I still cannot understand why.'. Only in these two occurrences the woman is engaged in the event as a female entity whose social power is evident in having the right to complain about how her body is treated, thus resulting in a serious investigation and threat of Tariq losing his job.

On the other hand, the second extreme of power is the powerlessness (both physical and social) of the Yemeni female character Muna who is not physically enabled to control her body in two senses, the first is when she is raped and the second when she is having convulsions, nor does she have the social power to complain about the rape. There are 78 concordances in which Muna's body parts are textually presented. Only in ten of these occurrences, $1^{\text {st }}$ person narration is employed and Muna talks about her own problem. However, even when she is given a chance to speak up, her sentences indicate inconfidence and helplessness. First, in the narration of her rape, she is, in fact, acted upon as in 'his huge smelly hand on my mouth', 'preferred to rape me from the back', 'on the mattress on my stomach', 'some security men found me asleep and woke me up'. Second, her sentences are epistemically modalized i.e. they include epistemic (modal) verbs (e.g. 'I wouldn't wear the niqab', 'I couldnt sleep for weeks' and 'I was to say that I just fell asleep in the car',), a negative evaluative adjective ('my legs went weak'), and an incomplete sentence weakened epistemically by 'think' ('I think I have a tear in my ...'). Muna's textual construction as emotionally helpless is also evident in four instances where she acts as the agent of the sentences but focalized submissively. For instance, 'she kept her eyes fixated on the floor', 'was drying her tears while listening to Tariq', 'slowly opened her eyes', and 'asked in a slow and sleepy voice where am I'. Although, in all of these examples, Muna is demonstrated as being on control over her actions but these actions denote emotional helplessness.

Not only is Muna constructed as emotionally helpless, but she is also socially overlooked by other men when she is talked about. Muna is represented as the topic of the men's talk. In 64 concordances, third person narration is employed in which Muna is focalized by a male gaze realized in the narrator, Tariq, her father, her husband, the minister and the general in prison. Muna is talked about with reference to her sexual activity in 36 concordances, first, when Tariq says 'mischievously' that her convulsions 'do have something to do with nerves'. Second, Muna's father and Tariq argue that her convulsions are due to her excessive sexual activity since she is a newlywed as in 'she did not have enough sleep on Thursdays', 'maybe staying up all night', and 'all this lack of sleep'. In the Yemeni culture, Thursday is considered a specialty for married people in the sense that it is followed by Friday, the weekend. In fact, most of the wedding parties take place on Thursdays.

In comparison to the representation of Tariq's female patient who is distanced from the stream of narration, Muna's body is much more textually engaged in terms of the notable use of the possessive adjectives 'her', 'your' and possessive case 'Muna's' (31 occurrences). However, in men's talk, Muna, as an individual, is distanced; she is talked about as a case. Muna's 'back', for example, is preceded by the definite article 'the' in 'was raped and from the back too', her 'blood' is also preceded by the definite article 'the' in 'spread of bacteria to the blood', and the demonstrative 'that' precedes 'tear' in 'when your trial comes up, that tear will have healed'.

Muna's physical disempowerment is evident when she is having her convulsions. In 20 concordances, Muna is represented as the receiver of the actions. Her body parts is, in fact, acted upon by Tariq who, for example, 'looked at her face', 'tried to lift her eyelids', 'forced one eye open', etc. Moreover, her father 'put his hand gently and lovingly on her forehead and prayed' and the male nurse, one of the three Indian nurses in the hospital, 'was now applying the electrodes on her scalp', 'managed to place six electrodes covering the front, middle and back of the scalp' etc. Even her body parts act by themselves without her, as a total being, being on control (14 concordances), for example, 'the muscle spasm in her jaw muscles prevented him', 'Muna's right thigh turned inward toward her left thigh and blocked his view', etc. There are also some passivized structures (4 in number) in which body parts are the agents and the identity of the doer of the actions is not revealed as in 'the eyes were tightly shut', 'the face was contorted', and 'there was no frothing at her mouth'. Even when Muna is the agent in 'if she had bitten it [tongue]', 'she's going to wake up soon', 'if she wet herself', she is unwillingly doing the actions in the sense that she is focalized by the male character Tariq. Such an interpretation supports the previous claim that Muna is depicted as a helpless character, though at a physical level here.

The male body. Out of the overall 697 instances of subcategory B1 384 are associated with the male body. There are 168 instances in which men are represented in relation to them having power (either physical or social), negotiating power with other men, or lacking control of themselves and of others. With reference to physical and social weakness, 130 concordances, which is $77 \%$ of the words in this category, represent the social and physical manipulation of the male characters such as Tariq, Tariq's father, Farook, the Yemeni lawyer and the hotel manager.

The most physically manipulated character here is the protagonist Tariq. Out of the 130 words in this category, 102 collocate with Tariq who is constructed as having no control over his body organs in two events. The first is when he is kidnaped, and about his experiences in jail and the second in the end when he loses consciousness. The description of the kidnap case and the kind of sufferings and tortures Tariq encounters while in prison in Yemen includes a total fragmentation of his body parts (e.g. hand(s), mouth, nostrils, ear(s), (left) shoulder(s), head, eyes, body, penis, feet, heart, legs, bladder, buttocks, waist, etc.). Although almost all parts of the body are fragmented, $25 \%$ concordances (26) are related to the parts of the body located in the head. There are also 10 concordances that are related to hands and fingers. These parts constitute the five body senses; hearing, seeing, 
tasting, smelling and touching and over representing them demonstrates Tariq's fear and anxiety of losing them.

Tariq's powerlessness to perform as a normal human being is, moreover, demonstrated via his incapability to personally satisfy his body needs including sleeping, peeing, as in 'he desperately needed to pee', 'he was unable to sleep', etc. In addition to not being able to meet his body needs, Tariq is represented as being affected by his tormentors as well as not having control over his body actions. Most of the grammatical concordances include statements where Tariq is acted upon. For example, 'his mouth' is 'sealed', 'his nostrils' are 'covered', 'his trousers' are 'pulled up over his legs', etc. The soldiers who kidnap Tariq are physically powerful and their strength is demonstrated in examples as the soldiers 'placed his hand over Tariq's mouth', 'then replaced his hand with a very thick sticky tape', one of the men 'had a duffle bag over his right shoulder' and the other 'stuffed yellow rubber ear plugs'. Tariq, moreover, has no complete control over his body as in 'his heart was pounding', 'Tariq's heart almost leaped out of his chest', 'the sweat forming underneath it', 'his fingertips could feel those of the other hand', 'his tongue was sticking to his palate', etc.

Beside being represented as a submissive character, Tariq is assigned other roles; he negotiates for social power in 21 concordances, more specifically in his conversations with Taha and the Airport agents. In these instances, Tariq is given a voice via $1^{\text {st }}$ person narration and is represented as negotiating for power. Tariq and Taha are given equal time to speak with 23 conversational roles to Tariq and 22 to Taha. Tariq, in this part of the novel speaks more than Taha (978 words in total) while Taha speaks $\% 50$ less, that (545 words in total).

\section{Describing characters in love scenes}

Magda and Tariq. In this category, the two main characters who encounter sexual intercourse with the protagonist are Magda and Gita. Out of the 43 concordances in which Magda's body parts are fragmented 36 are referred to while having sex with Tariq while there are 28 concordances that include Tariq's body parts. Magda's body is completely fragmented (e.g. 'her face', 'her neck', 'her head', 'her lips', etc.). Similarly, concordances of Tariq's body demonstrate high level of fragmentation notable in 'his eyebrows', 'his head', 'his right arm', 'into both hands', 'the back of his neck', 'his thick curly graying hair', etc.

The textual construction of the two characters is demonstrated in words in context inviting a few interpretations. First, this scene is focalized from a male perspective because there is no evaluation of the male body except of the 'thick curly graying hair' and 'raging organ' which are stereotypically the most important parts of which men brag about when it comes to their masculinity, thus they denote that the focalizer is male. On the other hand, the female body is evaluated in terms of sensual stereotypical beauty as the fullness of her lips 'full red lips', the smoothness of her skin 'warm and silky' and 'very smooth' which are sensed by men. In addition, the stimulated female vagina is referred to as 'that erogenous zone', and her orgasm is 'earth-shattering'. The use of such hyperbolic adjectives denotes the man's ability to satisfy a woman's desire. This is also evident in the idiomatic sentence 'Magda was clearly in seventh heaven'.

The second interpretation is relevant to the grammatical structure of the concordances in which the Tariq is assigned the role of the agent in performing most of the actions such as 'looked (down) at', 'put', 'sucked', 'feasted', etc. There are only two instances in which his body acts by itself as in 'his fingers advanced' and 'his raging organ was hovering'. What is worth noting here is Tariq's control over his body and Magda's while Magda is represented as the receiver of all of the actions. She, as a total being, is the agent in a few concordances (7) as in 'Magda raised her arms', 'crossed them behind his neck', 'trapping Tariq's hand', etc. Furthermore, even when she is assigned to play more roles in the intercourse, it is not her, as an individual being, who is participating rather her body parts as in, 'her eyelids half closed', 'Magda's legs stiffened', and 'her inner thighs came together'. Thus, she is represented as having no control over her body.

Gita and Tariq. The second female character who encounters physical intercourse with Tariq is Gita. Although Gita appears in two erotic scenes with Tariq, concordances of her body parts are only 22 in number which is twice less than the number of occurrences of Magda's body parts. Unlike the unequal distribution of anatomical parts of Tariq and Magda (28/36), Gita and Tariq almost have the same the number of concordances i.e. 14/16 respectively. The fragmentation of Gita's body is evident in 'her breasts', 'her (pink) nipples', etc. Tariq's demonstrated body parts include 'his neck', 'his groin', etc. Considering the evaluative structures associated with each of these characters, it is notable that like Magda, Gita's body is represented in terms of its sexual attractiveness so Gita's breasts are described as 'wellshaped, medium-sized' 'quite firm for her age', and her body is described as 'voluptuous', nipples are 'pink', orgasm is 'long' and lips are 'full'.

What is noteworthy is the difference in choice of words associated with the characters which represents the two women Gita and Magda differently, even Tariq is represented differently in each encounter. In the two instances, Tariq's sexual organ 'penis' is referred to as 'raging organ' with Magda but as 'erection' with Gita. Similarly, Magda's orgasm is described as 'earth-shattering' while Gita's is just 'very long'. Tariq, with Magda, is represented exaggeratedly while with Gita, he is just normal. This can be interpreted as Tariq is demonstrating his masculinity and manhood to an eastern woman, and bragging about it, thus creating a sense of patriarchy, but in Gita's case, his pride of his sexuality is not revealed since Gita is western. One more thing is that grammatical concordance demonstrates that Tariq and Gita have equal roles to play. For example, Gita is taking action in the intercourse, she is not simply a passive receiver, "was still wearing', 'held him over so firmly', etc. She has control over her body except in one example i.e. 'then came her very long orgasm' while Tariq does not have complete control over his body as in 'his palms cupping her breasts', etc. Tariq's superior attitude to Magda but collective stance with 
Gita is evident in the actions they do together. For example, there is one only instance of Tariq and Magda doing things together i.e. 'their lips met full on' in comparison to the five examples where Tariq and Gita do things collaboratively.

\section{Constructing cultural differences}

The female body. Culture difference is textually constructed around the female body in a number of concordances. In 15 hits of the female body parts, women belonging to both eastern and western cultures are demonstrated per their looks and sexuality. However, western(ized) women are represented as liberal while eastern women are ideologically reserved and discriminated. Similar to the first interpretative statement mentioned in the first category of this analysis, dressing code of the eastern women is repeatedly mentioned. Women in Yemen are compared to those in the west so they 'would be covered from head to toe' while women in Copenhagen go out nude as in 'middle-aged men ... enjoyed furtively ogling your nude body', 'they flirt and they enjoy sex and have lots of and have lots of orgasms'. Passivization in first statement critically indicates that it is not the women's choice to wear hijab. One more thing is that they highly depend on their husbands for 'giving her a roof over her head and feeding her'. This is an indication of gender inequality and discrimination and naturalizes the role that women have in the society, that they are always in need of a man.

Not only in terms of dressing but also with regard to greeting, women in both extremes differ. There is an emphasis on the positivity of the western women evident when Gita greets 'offering her hand', 'in a warm handshake' and Hanan, the westernized Lebanese woman, would show her kindness and open mindedness by extending 'her right arm' while not all Yemeni female receptionists would offer to shake hands with men.

The male body. Cultural differences are more prominent in associations with the male characters than with the female ones. There is a direct reference to the middle eastern, specifically the Yemeni, culture of the males' habits and manners. It is negatively depicted while the western one is positively portrayed through the attitudes of the protagonist Tariq.

There are instances in which Yemeni men are negatively constructed as depressed, having no manners and disgusting body habits. Disgusting habits include poking nose in public. For example, although Taher, the Libyan, is welcoming and nice, he pokes 'his nose with his little finger then rolling the mucus stuff into little balls'. The same habit is also done by Yemeni soldiers. Tariq and Colin, the westernized and western characters, find it disgusting. Another Yemeni cultural practice associated with disgust and negatively portrayed is chewing Qat.

Yemeni characters do also lack good eating manners. For example, the Yemeni man in the restaurant in pokes 'his teeth from time to time with his little finger', and 'as he chewed, his mouth kept opening rhythmically'. He also produces 'a loud burp'. Although Tariq has criticized manners in the Yemeni culture, he also talks about societies where 'peeing at the wall' is a norm while producing farts is considered bad habits.
Despite these negative depictions, male characters that belong to the Arab World are represented positively in terms of greeting, hospitality and kindness. They are associated with actions as extending, holding, offering and shaking 'hands', rising to 'their feet', smiling and kissing three times on the cheeks. Tariq, for example, 'found himself extending his hand of friendship to this soldier' and 'shook hands warmly'. 'Friendship' and 'warmly' are direct indications of Tariq's kind and welcoming attitude. Initiative is also seen when the eastern characters start the greeting process. These people are also positively represented as welcoming as in Taher 'had a huge smile on his face', the porter 'had a big smile on his face', 'the big genuine smiles that they see on the faces of Yemenis'. Their welcoming nature is also evident in 'kiss the men you meet, cheek to cheek'.

Although these cultural practices seem pleasant and warm, their representation in the context demonstrate Tariq's critical attitude towards them; they indicate superficiality and hypocrisy. Tariq, for instance, has a critical attitude in the use of evaluative adverb 'worse' in 'it was even worse in another emirate one day' indicating that he does not favor the exaggeration in greeting in the Yemeni as well as Arabic society represented by Emirates in the context where people 'kiss the sheikh on his nose'.

Despite the association of negative manners with the Yemeni characters, the protagonist Tariq, also Yemeni, is being represented as a westernized man. He, for example, drinks wine and follows the rituals that precede drinking such as holding the glass of wine 'up to his nose' in order to sniff it before drinking, half closing 'his eyes', pursing 'his lips', shaking 'his head in approval' and enjoying the taste feeling it 'on his palate'. The positive semantic prosody of 'approval' and 'enjoying', for example, denote a positive stance of the custom in particular, and the west in general.

The Yemeni culture is also talked about in terms of how men and women behave in public. Manifestations of the culture through body habits is seen in examples as when men would be seen in the streets or even at work 'holding hands and talking loud', while couples are not seen holding hands together which denotes a derogatory attitude towards women. Another example of the disparaging customs of the Yemeni society is related to men controlling their wives, dealing with them as possessions. For example, the professor whose wife Tariq sat next to during a ride was furious with 'obvious facial signs of distress', stopped the car and furiously asked her to swap places with him. Also, Abu-Bakr claimed that his wife does not know what sickness she is suffering but was stopped by Tariq who asked 'is it your head'?

On the other hand, the western male character Brian deals with Lubna with much love and respect as seen in 'Lubna and Brian left, holding hands'. Ways of treating women in the two different cultures are notable. There is one instance in which love is expressed that is when Farook, Muna's father, 'put his hand gently and lovingly on her forehead and prayed'. Although there is stance denoted in the positive evaluative adverbs 'gently' and 'lovingly', Muna is still under the 'prying eyes' of her father while she is having the medical check up. 


\section{CONCLUSION}

The main objectives of this paper included analysing the manners in which the bodies of both the female and male characters are introduced and described in the FFFS Corpus; investigating the ideological implications of power relations between characters; and scrutinizing differences and similarities in representation of the gendered characters belonging to eastern and western cultures. Thus, these issues were examined and the following conclusions were reached.

First, female and male characters are introduced via the fragmentation of their body parts in the examined corpus. Female characters are introduced in relation to their appearance. The western(ized) female characters are talked about in terms of their sexual availability and attractiveness and the eastern female ones are introduced in terms of their dress code and religious affiliation. On the other hand, the male characters are viewed via their origin, colour, height and weight. Moreover, there is a detailed description of their clothes. They are also depicted in terms of their potentialities such as decision making, respectability, (not) possessing social power, etc., physical abilities or deficiencies.

Second, with regard to power representation, both Muna and Tariq, the female and male protagonists, are demonstrated as powerless. Muna's anatomical parts involved are acted upon. She is also emotionally helpless and socially overlooked. Tariq is physically manipulated, incapable of satisfying physical needs and is having no control over his body actions. However, while Muna loses physical and social control to men, Tariq loses only physical control but negotiates for social power. In either case, it is a battle of supremacy between males but an issue of exercising males' power on the female.

Third, out of the three erotic scenes of the novel, one scene is between the westernized Magda and Tariq where the male is the dominant while the female is the dominated. The scene is focalized from the male gaze in the sense that there is an evaluation of the female's sensual beauty that is seen and touched. Furthermore, the male is assigned the role of the agent in performing actions while the female is assigned a few roles but not her as an individual rather her body that acts. The other two scenes are between the western Gita and Tariq. Here, there is almost a similar number of concordances. In the scene, Gita takes action and Tariq is not having complete control over his body. Furthermore, there is no sense of pride of his manhood and both characters have a collective stance towards each other.

Fourth, given the cultural construction of the characters, all females are depicted via their looks and sexuality. However, there is a taxonomy of presentation where eastern females are represented as reserved and discriminated while the western(ised) are nice, open minded and liberal. On the other hand, the Yemeni males have no manners, disgusting body habits, no good eating manners. Their welcomeness and hospitality are negatively depicted, however, the western(ised) customs and habits are approved.

\section{REFERENCES}

Butler, J. (1990). Gender Trouble: Feminism and the Subversion of Identity. London: Routledge.

Butler, J. (1993). Bodies that Matter: On the Discursive Limits of "Sex". London: Routledge.

Butler, J. [Lbtavares Tavares]. (2015) Judith Butler's conference entitled "Why bodies matter" on June $2^{\text {nd }} 2015$ in the context of the celebrations of "gender trouble"'s $25^{\text {th }}$ Anniversary in Teatro Maria Matos in Lisbon [Video file]. Retrieved from https://www.youtube.com/ watch? $\mathrm{v}=\mathrm{IzWWwQDUPPM} \& \mathrm{t}=23 \mathrm{~s}$.

Brown, C. A. (2012). The Black Female Body in American Literature and Art: Performing Identity. New York: Routledge.

Ghanem, Q. (2011). Final Flight from Sana'a. Ottawa: Baico Publishing.

Green, M. (2016). Silence of the limbs: Dismemberment, female bodies, and literary pieces. Oklahoma: University of Oklahoma dissertation. Retrieved from https://shareok.org/handle/11244/34684.

Guldin, R. (2002). The dis-membered body: Bodily fragmentation as a metaphor for political renewal. Physis: Revista de Saúde Coletiva 12(2): 221-234.

Innes-Parker, C. (1995). Fragmentation and reconstruction: Images of the female body in Ancrene Wisse and the Katherine Group. Comitatus: A Journal of Meideval and Renaissance Studies 26(1). Retrieved from http:// escholarship.org/uc/item/9pv651nq.

Jeffries, L. (2007). Textual Construction of the Female Body: A Critical Discourse Approach. Basingstoke: Palgrave Macmillan.

June, P. B. (2010). The Fragmented Female Body and Identity: The Postmodern, Feminist, and Multiethnic Writings of Toni Morrison, Theresa Hak Kyung Cha, Phyllis Alesia Perry, Gayl Jones, Emma Pérez, Paula Gunn Allen, and Kathy Acker vol. 56. New York: Peter Lang Publishing.

Kappeler, S. (1986). The Pornography of Representation. Cambridge: Polity Press.

Katrak, K. H. (2006). Politics of the Female Body: Postcolonial Women Writers of the Third World. New Brunswick, NJ, and London: Rutgers University Press.

Leech, G. and Fallon, R. (1992). Computer corpora - What do they tell us about culture? ICAME Journal 16.

Mills, S. (1995). Feminist Stylistics. London: Routledge.

Montoro, R. (2012). Chick Lit: The Stylistics of Cappuccino Fiction. London: Bloomsbury Publishing.

Morguson, A. (2012). All the pieces matter: Fragmentation-as-agency in the novels of Edwidge Danticat, Michelle Cliff, and Shani Mootoo. Indiana: Indiana University MA thesis. Retrieved from http://hdl.handle. net/1805/3218.

Walsh, C. (2001). Gender and Discourse: Language and Power in Politics, the Church and Organizations. London: Longman. 